\title{
Innovation Strategy to Improve China's Urban Public Crisis Management Mechanism
}

\author{
Yongchang Ren \\ College of Information Science and Technology, Bohai University, Jinzhou, 121013, China \\ 1213552916@qq.com
}

Keywords: urban management; public crisis; management mechanism; innovation strategy

\begin{abstract}
The research of innovation strategy of urban crisis management mechanism is benefit for the government to make timely, accurate and scientific decision-making when occurs public crisis to enhance the effectiveness of crisis management. Specific innovation strategies include: improving evaluation mechanism after occurring public crisis, building multivariate coordination joint mechanism of crisis management, perfecting the principles of government's public crisis management mechanism, strengthening citizen participation mechanism of public crisis management, improving information dissemination mechanism of public crisis management and improving decision-making mechanism of public crisis management and so on. Results of this study enrich and supplement theories and methods of existing urban crisis management in theory and can provide a scientific basis for government's decision-making on crisis management in practice.
\end{abstract}

\section{Introduction}

"Public crisis" is an abnormal state norm of states and events with high uncertainty, instability and threatening, which can cause serious damage to lives and properties, arouse widespread public psychological panic, disrupt normal social order and public relations and undermine basic social values. Public crisis must meet the following four conditions to be called public crisis: huge damage to people and property, the public's tension state, out of control for social order, the public's trust and faith crisis. "Mechanism" originally referred to the structure and working principle of machines, now it is widely used in the natural and social phenomena, referring to its internal organization and the law of operational changes. Due to the problems of that China's public crisis management efficiency is not high, the level is poor, the system is not perfect, lacking the awareness of crisis management, legal missing crisis management and mishandling public crisis information and other issues are existing, this paper, based on the characteristics and experiences of foreign public crisis management, innovation strategy of improve China's urban public crisis management mechanism is proposed to lay the foundation for better public crisis management work and provide theories and methods for the effective operation of the public crisis management.

\section{Review of Research Status}

The research content of public crisis management theory in contemporary western academia focuses on two areas: research methods, compared to the past that mainly used research methods of political science, more emphasizes on the integrated use of statistics, political science, management and sociology and other disciplines now, and has initially formed the general pattern for government to manage public crisis; research trends gradually shift from qualitative research to quantitative research. Western countries in the past mainly focused on the issues study such as political stability, now it is turning to build crisis warning systems and build mathematical models of crisis management.

The construction of China's public crisis management mechanism is still in its infancy, compared to western developed countries that have perfect crisis management system and sophisticated crisis management mechanism, there are many problems in the China public crisis management. The majority of our local government's emergency response system is just the supplement for original disaster management system. Overall public crisis management has many problems, and there is a 
considerable distance from theory assumption of public crisis governance, the research effort for it still needs to be strengthened. China's public crisis management mechanism exists the following questions [1,2]:

(1) The interdisciplinary research is not enough. Diversity and complexity of the crisis form determines the research in this field must use theories and methods of political science, economics, management, sociology and ecology, psychology and other disciplines. At present, China's research mainly confines to the field of political science and management, so as to lead to narrow of research perspective and restrict the innovation of new areas' expansion and research.

(2) Research field and range is narrow. In the research field and range, at present China mainly puts government crisis management as the core and urban crisis as the main object, but the research on crisis management for rural areas, especially in minority areas, is not enough. Currently public crisis management research mainly in the macro level or the city limitation, it is difficult to apply in the majority ethnic areas with cultural diversity and geographical culture complexity.

\section{Significance and Value of Research}

Significance and value of research is reflected in two aspects:

(1) Theoretical significance. Theoretical research of crisis management is still in its infancy, how to improve our crisis management mechanism becomes a serious problem. Especially in the 21st century, the world economy and political situation have undergone great changes, global various crisis issues in social transformation are emerging, which put forward new demands for theoretical research of crisis management, in this context, theories and methods of public crisis management are formed and developed. Public crisis management is remarkable and is an important theoretical issue in social activity. In the situation of imperfect public crisis management research, systematic study public crisis management mechanism has important theoretical significance, its reflection mainly in two aspects: first, systematic studying management mechanism issues in public crisis management theory and updating public crisis management concept. Public crisis management mechanism uses the basic theory and concept of management to analysis all the disadvantages during public crisis management and deepen people's understanding for the public crisis management activities, as well as introduce new theories and methods for public crisis management. Second, systematic and scientific analyze and research to build new public crisis management mechanism. People sum up a series of theories and methods of public crisis management after numerous failures and successes. Government and community should take advantage of these theories and methods to guide crisis management, and verify and rich it in practice to form a scientific and rational public crisis management mechanism ultimately.

(2) Practice significance. Crisis management is a highly practical and applied discipline, from the successful experience of foreign countries, our country should establish socialist public crisis management mechanism with Chinese characteristics, so as to provide institutional guarantee for the scientific management of public crisis. Practical significance mainly is reflected in two aspects: first, study on public crisis management mechanism can provide reference for public crisis management activities. The social crisis, health crisis, economic crisis, financial crisis, faith crisis and terrorist attacks continue occurring, and these series of emergencies belong to crisis. Public crisis management requires government and social organizations to quickly organize forces and make different respond for different regions when face crises. There is a big flaw in China's public crisis management mechanism, such as the ability to cope with the crisis is insufficient clearly. Therefore, the study of this subject is to provide a reference for the public crisis management activities. Second, public crisis management mechanism can provide ideological guidance for carrying out public crisis management. Public crisis management can be carried out by public crisis management mechanism to reduce unnecessary detours. Public crisis management in today faces new situations and new problems, only study new mechanisms of public crisis management as soon as possible to be able to strive for initiative position, reduce losses and maintain social stability. Actively explore new models of public crisis management to meet time's develop, which plays an important role in maintaining social stability and protecting people's lives and properties. 


\section{Innovation Strategy of Mechanism}

China is still in the primary stage of socialism, the law system of society is not mature, public crisis management mechanism is not fully developed, study system theory and management model of China's urban public crisis management, learn the characteristics and experiences from the foreign urban crisis management, combine with China's specific conditions to improve innovation strategy China's urban public crisis management mechanism as follows [4-6]:

(1) Improving evaluation mechanism after occurring public crisis. Impact of the crisis and disaster is difficult to predict, scientific designing evaluation index system of public crisis management mechanism, which can ensure public crisis management in a scientific, standard and normal way to enhance the means and level of crisis management. Scientific evaluation index system is used to combine social with self-assessment to enhance the quantify ability of public crisis management, make sure the role of government agencies faced with crises, directly face the challenges of crisis management and strengthen government public crisis management capabilities. After crises, crisis evaluation and assessment mechanism aims to evaluate the whole process of crisis management and learn lessons, which can lay the foundation for further improving the performance of crisis management department and constantly reshaping and improving crisis learning and innovation mechanism. Government crisis management departments should set up a special body, its responsibilities are to evaluate damaged departments and individuals during deal with crises, evaluate government crisis' participants and usage of property and human, evaluate measures' effectiveness that used during deal with crises and evaluate the impact of the crisis to the city's economic management and development planning. Government optimizes the allocation of resources based on the assessment results to determine the order of construction and development after the crisis.

(2) Building multivariate coordination joint mechanism of crisis management. From the geographical perspective, the impact of the crisis may spread from one administrative division to another administrative division; from the perspective of development, the crisis may also lead derivative and secondary disasters, disaster chain will be formed. Multiple disaster chains are entwined to form a disaster network. The current crisis management takes the government as leading, because of the issues, such as government administrative management system, information communication and resource constraints, and it is difficult to play the role of social forces to respond crisis together. Multivariate coordination joint mechanism of public crisis management refers to achieve coordination joint operation model among various components through that the government optimizes the allocation of multiple subjects' resources, rational integrates responsibilities and takes regulations and organization rules as guarantee. Using multivariate coordination joint mechanism to achieve effective integration of multivariate participants in public crisis management activities, and make it a force to avoid inefficient duplication or absence phenomenon in crisis management, reduce costs, improve efficiency and achieve public interests. The most important role of a structure rational, operation efficient multivariate coordination joint mechanism is to realize the dynamic combination of command and coordination system, disposal implementation system, resources support system, information management system and decision support system crisis management system in the crisis management system to protect the mutual cooperation and mutual support among these systems.

(3) Perfecting the principles of government's public crisis management mechanism. There are four aspects in the following: first, it is people-oriented, prevention-oriented principle. By protecting and saving public lives in the first place, taking the detection, warning and prevention of crisis as a central part of government public crisis management, prevention-oriented and do routine inspection and supervision to improve the overall prevention system and reduce the occurrence of variety crises. Second, it is the principle of unified command and operation coordination. Public crisis management implements scientific decision-making, unified leading and unified command, their response is timely and measures are resolute, they are co-operation and coordinated operation, integrated using regulating means, such as administration, legal, economy and media, to deal with crises, protect social security and stabilizing social order. Third, it is the principle of clear 
responsibilities and rights, administration according to law. Emergency function institutions must deal with public crises by departments' duties, and it is stuck to cooperation, division of responsibility, centralized management to make clear responsibilities. Meanwhile, public crisis management must be according to law, this not only is the basic guarantee of public rights, but also is the basic requirement for effective operation of government. Fourth, it is the principle of resource integration and information sharing. Through network information resources and business application system construction, strengthen the integration of departments and business systems and ensure that material resources, human resources and other resources can be called immediately in a state of emergency to achieve full integration.

(4) Strengthening citizen participation mechanism of public crisis management. The absence of citizens' safety awareness and security capabilities are not conducive to the prevention and control of public crisis. In the process of crisis management, direct participation of citizens can understand the process of crisis situation and crisis management timely, collective wisdom will be developed to improve decision-making level of government public crisis, raise awareness of citizens' rights and duties, enhance social responsibility of citizens, promote the implementation of democratic conviction and raise national awareness, the purpose of preventing public crises can be fundamentally achieved. Strengthen citizen participation of public crisis management will directly relates to the legitimacy basis of the government and the people's safety and welfare, it also directly affects the country's political, economic stability and development. Citizens participation mechanism in public crisis management can be strengthened from the following aspects: educating citizens' crisis sense, shaping developed citizens emergency culture; strengthening the organization of citizens' participation in public crisis management, reducing and preventing disorder and blindness of citizen participation; developing citizen society and public spirit, promoting citizen' responsibility awareness in public crisis management; improving information communication mechanism, protecting citizens' right to know; establishing incentive mechanism of citizen participation, inspiring the enthusiasm of citizen participation in public crisis management; establishing perfect legal mechanism to protect the legalization of citizen participation in public crisis management; improving the administrative accountability system, improving the initiative of citizen participation introduced by government officials.

(5) Improving information dissemination mechanism of public crisis management. Secondary crisis caused by public crisis information dissemination mismanagement brings great challenges to government and social stability. Therefore, unblocking and dredging public opinion communication channels, improving the public crisis dissemination management mechanism and improving and using information management system to achieve the effective dissemination of crisis information, which are the issues that government must seriously face and consider. The roles of improving public crisis information dissemination management mechanism are as follows: first, it is beneficial to defuse crisis. By collecting, tidying and analyzing information, problems are identified timely so as to do response preparations to eliminate crisis in the bud; second, it is beneficial to make right decisions. Keep abreast of the development of the crisis and people's reality situation and other information to help make the right decisions; third, it is beneficial to create synergy effect. After public crisis, people mostly in a state of panic, through the crisis information dissemination, government crisis policies should be conveyed effectively to seek support from general public to achieve the purpose of the upper and lower linkage and crisis elimination; fourth, it is beneficial to mobilize more forces to participate in the rescue. Timely, open and transparent crisis information dissemination in crisis management can seek support and help from central government, other local governments, other organizations and social forces to shorten the processing time of crisis and reduce crisis losses.

(6) Improving decision-making mechanism of public crisis management. Decision-making is the core of public crisis management, public crisis management of our governments mostly is in low decision-making level. Decision-making rarely uses modern decision-making techniques, such as artificial intelligence technology, information technology, countermeasures science, operations research and system analysis, case library of crisis management and database of post-disaster 
reconstruction are also lagging behind, we must strengthen decision-making system construction of crisis management. First, improve the quality of crisis policymakers. Policymakers' quality is very important, and they must have the macro-control capability, innovation capability, rapid and timely response capability, resourceful and listening communication capability, unflappable mental ability and scientific decision-making ability to foresee. At the same time, we must raise awareness of crisis decision-making and mental endurance capability to enhance perception, adaptation and resistance ability for crisis decision-making groups. Then, optimize crisis decision organizations. Crisis decision-making power should appropriately focus on comprehensive core coordination mechanism to enhance the integration ability of decision-making system and pay attention to the coordination and communication of decision-making system; strengthening think tank of crisis decision-making, providing timely and effective crisis evolution context and information of development prospects to create conditions for the government crisis management' correctness and scientificity; improving crisis decision-making capability of local governments to create certain participation constraints and incentive-compatible mechanisms for behavior selection of local governments.

\section{Conclusion}

This paper uses literature search, theoretical analysis, the research of innovation strategy of urban public crisis management mechanism as the main content and main line, to solve theory and method problems of China's urban public crisis management mechanism from the perspective of crisis prevention, crisis response, and change the crisis as an opportunity. The research of scientific urban crisis management mechanism is benefit for the government to make timely, accurate and scientific decision-making when occurs public crisis to reduce the negative consequences to a minimum and improve the effectiveness of crisis management. This paper aims to study and explore new theories and new ways of urban public crisis management mechanism to solve the key issues of urban public crisis emergencies, reduce decision risk and improve the government ability, especially to cope with complicated situations and deal with crises. Theoretically further enriching and supplementing theories and methods of existing urban crisis management and providing a scientific basis for government's decision-making on crisis management in practice.

\section{Acknowledgment}

This work is supported by social science fund project of Liaoning province (L12BZZ009): Research on management mechanism for urban public crisis.

\section{References}

[1] Z. C. Jiang, "Research on Emergency Decision - making Theory and Coping Mechanism of Public Crisis Management in Urban Agglomeration," Doctor's Shanghai University, 2014.

[2] Dominique Bouf, Bruno Faivre d'Arcier, "The looming crisis in French public transit," Transport Policy, vol. 42, no. 8, pp. 34-41, 2015.

[3] Naim Kapucu, "Disaster and emergency management systems in urban areas," Cities, vol. 29, no. 1, pp. 41-49, 2012.

[4] X. M. Hu, B. Y. Tang, "Standards system theory and process theory of public crisis management -- Based on the stakeholder analysis with Swarm," Wuhan University Journal (Philosophy \& Social Sciences), vol. 30, no. 10, pp. 119-121, 2010.

[5] X. Peng, Y. C. Ren, "Basic Architecture of Government on Urban Emergency Management System," Computer Technology and Development, vol. 23, no. 2, pp. 207-210, 2013.

[6] X. S. Han, "Decision-making models and operational Mechanisms of Government on Urban Emergency Management," Doctor’s degree of Harbin Institute of Technology, 2009. 